Article

\title{
Primary Phosphines and Phosphine Oxides with a Stereogenic Carbon Center Adjacent to the Phosphorus Atom: Synthesis and Anti-Markovnikov Radical Addition to Alkenes
}

\author{
Toshiaki Murai ${ }^{1, *}$,, Ryota Wada ${ }^{1}$, Kouji Iwata ${ }^{1}$, Yuuki Maekawa ${ }^{1}$, Kazuma Kuwabara ${ }^{1}$ and Mao Minoura ${ }^{2}(\mathbb{D}$ \\ 1 Department of Chemistry and Biomolecular Science, Faculty of Engineering, Gifu University, \\ Yanagido, Gifu 501-1193, Japan; x4521106@gmail.com (R.W.); r3023008i@yahoo.co.jp (K.I.); \\ yukimae0209@gmail.com (Y.M.); erosiony1022@gmail.com (K.K.) \\ 2 Department of Chemistry, College of Science, Rikkyo University, Nishi-ikebukuro, \\ Toshima-ku, Tokyo 171-8501, Japan; minoura@rikkyo.ac.jp \\ * Correspondence: mtoshi@gifu-u.ac.jp; Tel.: +81-58-293-2614
}

\section{check for} updates

Citation: Murai, T.; Wada, R.; Iwata, K.; Maekawa, Y.; Kuwabara, K.; Minoura, M. Primary Phosphines and Phosphine Oxides with a Stereogenic Carbon Center Adjacent to the Phosphorus Atom: Synthesis and Anti-Markovnikov Radical Addition to Alkenes. Organics 2021, 2, 395-403. https://doi.org/10.3390/org2040023

Academic Editors: Tomasz K. Olszewski and Michal Szostak

Received: 29 August 2021

Accepted: 26 October 2021

Published: 16 November 2021

Publisher's Note: MDPI stays neutral with regard to jurisdictional claims in published maps and institutional affiliations.

Copyright: (c) 2021 by the authors. Licensee MDPI, Basel, Switzerland. This article is an open access article distributed under the terms and conditions of the Creative Commons Attribution (CC BY) license (https:// creativecommons.org/licenses/by/ $4.0 /)$.

\begin{abstract}
Organophosphorus compounds with stereogenic phosphorus and carbon atoms have received increasing attention. In this regards, primary phosphines with a stereogenic carbon atom adjacent to the phosphorus atom were synthesized by the reduction in phosphonates and phosphonoselenoates with a binaphthyl group. Their oxidized products, i.e., phosphine oxides with a stereogenic tetrasubstituted carbon atom, were found to undergo $\mathrm{BEt}_{3}$-mediated radical addition to cyclohexene to give $P$-stereogenic secondary phosphine oxides with a diastereoselectivity of 91:9. The products were characterized by ordinary analytical methods, such as Fourier transform infrared spectroscopy; ${ }^{1} \mathrm{H},{ }^{13} \mathrm{C}$, and ${ }^{31} \mathrm{P}$ NMR spectroscopies; and mass spectroscopy. Computational studies on the phosphorus-centered radical species and the obtained product implied that the thermodynamically stable radical and the adduct may be formed as a major diastereomer. The radical addition to a range of alkenes took place in an anti-Markovnikov fashion to give $P$-stereogenic secondary phosphine oxides. A variety of functional groups in the alkenes were tolerated under the reaction conditions to afford secondary phosphine oxides in moderate yields. Primary phosphines with an alkenyl group, which were generated in situ, underwent intramolecular cyclization to give five- and six-membered cyclic phosphines in high yields after protection by $\mathrm{BH}_{3}$.
\end{abstract}

Keywords: anti-Markovnikov radical addition; five- and six-membered cyclic phosphines; primary phosphine oxides; primary phosphines

\section{Introduction}

Organophosphorus compounds, and particularly those with three or four substituents on the phosphorus atom, i.e., tertiary phosphines, phosphine oxides, and their isologues, are of great importance in organic synthesis and medicinal chemistry [1-3]. The synthesis and reactions of primary phosphines [4-18] and phosphine oxides [19-21] which contain two phosphorus-hydrogen $(\mathrm{P}-\mathrm{H})$ bonds have received increasing attention because these highly reactive bonds undergo various types of phosphorus-carbon $(\mathrm{P}-\mathrm{C})$ bond-forming reactions. Their highly efficient addition reactions to alkenes have been achieved with transition metal catalysts [22-24]. A radical reaction involving phosphorus-centered radicals generated in situ is a classical method for P-C bond formation [25-30]; however, the use of primary phosphines and phosphine oxides in a radical reaction is relatively rare compared to that of secondary phosphines and phosphine oxides [31-38]. The stereochemistry on a phosphorus atom has not received much attention, despite the fact that the introduction of at least three different substituents to the phosphorus atom gives rise to the stereogenic center on the phosphorus atom. During the course of our studies on main group chemistry $[39,40]$, we have intensively studied the synthesis and applications 
of organophosphorus compounds with a binaphthyl group [41-45] and recently reported that the deprotonation and alkylation of phosphonoselenoates and phosphonates with a binaphthyl group creates stereogenic secondary and tertiary carbon centers adjacent to the phosphorus atom with high diastereoselectivity (Scheme 1a,b) [46]. The resulting products are potentially available as precursors of primary phosphines since phosphorus-oxygen bonds are readily reduced to $\mathrm{P}-\mathrm{H}$ bonds.

a) Construction of stereogenic secondary carbon atom adjacent to the phosphorus atom (previous work)

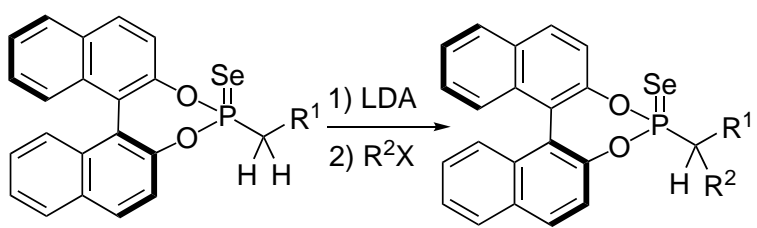

c) Synthesis of primary phosphines (this work)

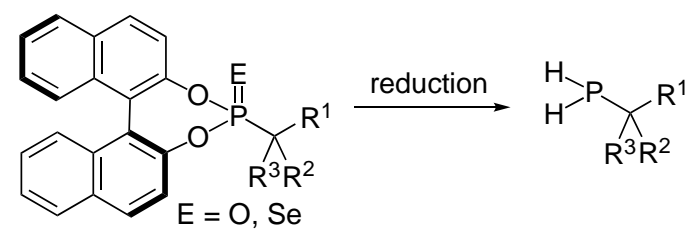

b) Construction of stereogenic tertiary carbon atom adjacent to the phosphorus atom (previous work)

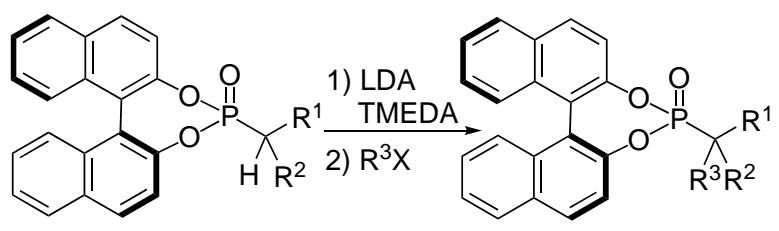

d) P-C bond formation (this work)

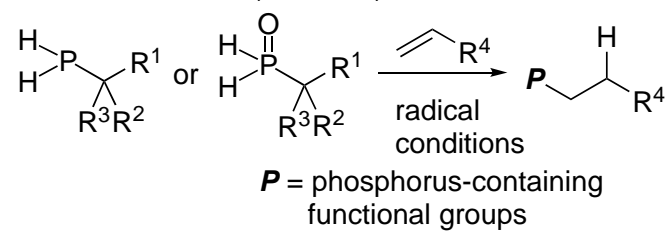

Scheme 1. Organophosphorus compounds having stereogenic carbon atoms adjacent to the phosphorus atom.

Herein, we report the generation of primary phosphines and their oxides with a stereogenic carbon center adjacent to the phosphorus atom and their radical addition reaction to alkenes to give $P$-stereogenic secondary phosphine oxides (Scheme $1 \mathrm{c}, \mathrm{d}$ ).

\section{Materials and Methods}

General Remarks: The IR spectra were obtained on a JASCO FT-IR spectrophotometer. The ${ }^{1} \mathrm{H}$ NMR spectra were measured on a JEOL AL400 (400 MHz), ECX-400P (400 MHz), or ECA-500 (500 MHz) in $\mathrm{CDCl}_{3}$. Chemical shifts of protons are reported in $\delta$ values referred to tetramethylsilane as an internal standard in $\mathrm{CDCl}_{3}$, and the following abbreviations are used: s: singlet, $\mathrm{d}$ : doublet, $\mathrm{t}$ : triplet, and $\mathrm{m}$ : multiplet. The ${ }^{13} \mathrm{C}$ NMR spectra were measured on a JEOL AL400 (100 MHz), ECX-400P (100 MHz), or ECA-500 (125 MHz) in $\mathrm{CDCl}_{3}$. The ${ }^{31} \mathrm{P}$ NMR spectra were measured on a JEOL AL400 (162 MHz), ECX-400P (162 MHz), or ECA-500 (202 MHz) in $\mathrm{CDCl}_{3}$ with $85 \% \mathrm{H}_{3} \mathrm{PO}_{4}$ as an external standard. All spectra were acquired in the proton-decoupled mode. The mass spectra (MS) and high resolution mass spectra (HRMS) were taken on a JMS-700 mass spectrometer. Preparative recycling gel permeation chromatography (GPC) was carried out using $\mathrm{CHCl}_{3}$ as the eluent. All these instruments are made in Japan.

Materials: Lithium aluminum hydride, allyl alcohol, allyltrimethylsilane, 6-bromo1-hexene, 5-hexene-2-one, and 1,5-hexadiene were purchased from Tokyo chemical industry Co., Ltd., Tokyo, Japan. Magnesium sulfate anhydrous $\left(\mathrm{MgSO}_{4}\right), \alpha, \alpha^{\prime}$-azobisisobutyronitrile, hexane, tetrahydrofuran (THF) dehydrate, toluene, ethyl acetate, chloroform, and triethylborane 1.0 M solution in hexane were purchased from Kanto Chemical Co., Ltd., Tokyo, Japan. Chloroform-d, triethylborane 1.0 M solution in THF, and 1,2:3,4-di-Oisoprorylidene- $\alpha$-D-galactopyranose were purchased from Aldrich Chemical Company, Inc., Milwaukee, WI, USA. Cyclohexene was purchased from Nacalai Tesque Inc., Kyoto, Japan. Dichloromethane and alumina activated were purchased from Waco Inc., Tokyo, Japan. All manipulations were carried out under argon atmosphere.

\section{Results and Discussion}

Initially, phosphonate $\left(S_{\mathrm{ax}}, S_{\mathrm{p}}\right)$-1a with a trisubstituted carbon atom adjacent to the phosphorus atom was reduced with lithium aluminum hydride (LAH) (Scheme 2) [47]. 


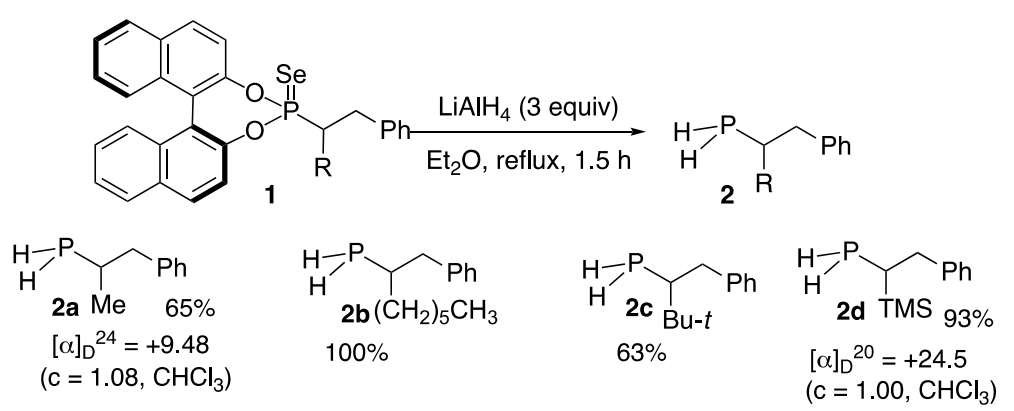

Scheme 2. Reduction of phosphonoselenoates 1 with $\mathrm{LiAIH}_{4}$.

The reaction proceeded smoothly under reflux in diethyl ether to give the primary phosphine $2 \mathbf{a}$ in $65 \%$ yield. The use of diastereomerically enriched substrate $1 \mathbf{a}(\mathrm{dr}>95: 5)$ was expected to give an enantiomerically enriched product $\mathbf{2 a}$. In fact, $\mathbf{2 a}$ and $\mathbf{2} \mathbf{d}$ showed a specific rotation of +9.48 and +24.5 , respectively, but the enantiomeric purity of $2 \mathbf{a}$ was not determined because of its lability under HPLC analytical conditions and in the presence of chiral shift reagents. The efficiency of the reduction was further proved in the reaction of $\mathbf{1 b}-\mathbf{1 d}$ with LAH leading to the formation of $\mathbf{2 b}-\mathbf{2} \mathbf{d}$. The reduction in phosphonate 3 having a tetrasubstituted atom adjacent to the phosphorus atom with LAH also took place to give the corresponding primary phosphine 4 (Scheme 3).

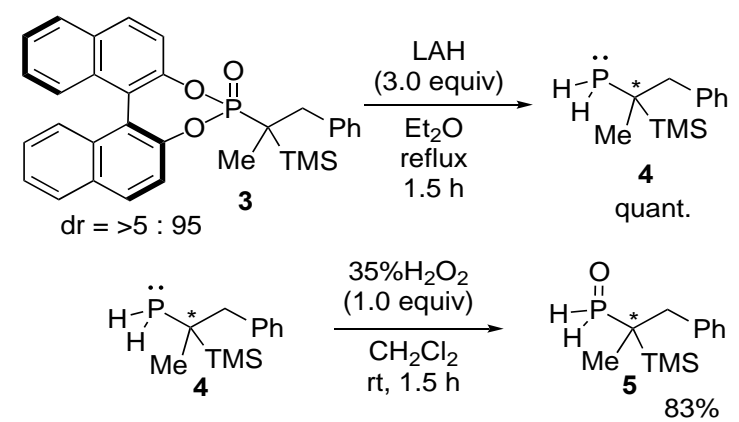

Scheme 3. Synthesis of primary phosphine and phosphine oxide $\left({ }^{*}\right.$ shows a chiral center and the carbon atom adopts either $\mathrm{R}$ or $\mathrm{S}$ configuration).

The oxidation of primary phosphine $\mathbf{4}$ selectively gave primary phosphine oxide 5 with high efficiency, although similar oxidation of $\mathbf{2}$ with a trisubstituted carbon atom at the phosphorus atom did not give the desired oxides with high efficiency. The absolute configuration of the product $\mathbf{5}$ was not determined at this point, but was later determined by converting it to an alkene adduct.

Radical addition of the resulting primary phosphines 2 and 4 and phosphine oxide 5 to alkenes under radical reaction conditions was then carried out. However, unlike the reported addition reaction of primary phosphines with an aromatic group and a tertiary alkyl group on the phosphorus atom [30], the AIBN-mediated reaction of primary phosphines $\mathbf{2}$ and $\mathbf{4}$ to alkenes gave complex mixtures containing a small amount of the expected adducts. In contrast, the reaction of primary phosphine oxide 5 with cyclohexene (6a) gave an isolable product $7 \mathbf{a}$ (Table 1). 
Table 1. Optimization of radical addition ${ }^{[a]}$.

\begin{tabular}{|c|c|c|c|c|c|}
\hline \multirow[b]{2}{*}{ Entry } & \multirow{2}{*}{${ }_{\text {Redical Initiato }}^{\mathrm{O}}$} & \multicolumn{2}{|c|}{$\begin{array}{c}\begin{array}{c}\text { radical } \\
\text { initiator } \\
(1.1 \text { equiv })\end{array} \\
\text { solvent } \\
\text { temp. } \\
22 \mathrm{~h}\end{array}$} & $\underbrace{\mathrm{O}}_{\text {He }} \overbrace{\mathrm{TMS}}^{\mathrm{P}}$ & \multirow[b]{2}{*}{$\mathrm{dr}{ }^{[b]}$} \\
\hline & & Solvent & Temp & Yield [\%] ${ }^{[b]}$ & \\
\hline 1 & AIBN & $\mathrm{MeOH}$ & rt & $0[\mathrm{c}]$ & \\
\hline 2 & $\mathrm{BEt}_{3}$ & $\mathrm{MeOH}$ & $\mathrm{rt}$ & 10 & \\
\hline 3 & $\mathrm{BEt}_{3}$ & $\mathrm{MeOH}$ & $0{ }^{\circ} \mathrm{C}$ & 62 & 91:9 \\
\hline 4 & $\mathrm{BEt}_{3}$ & $\mathrm{MeOH}$ & $40{ }^{\circ} \mathrm{C}$ & 75 & $91: 9$ \\
\hline 5 & $\mathrm{BEt}_{3}$ & $\mathrm{CH}_{2} \mathrm{Cl}_{2}$ & rt & 12 & \\
\hline 6 & $\mathrm{BEt}_{3}$ & THF & $\mathrm{rt}$ & $0^{[c]}$ & \\
\hline
\end{tabular}

[a] Reaction conditions: 5 ( $0.5 \mathrm{mmol}, 1$ equiv), $\mathbf{6 a}$ ( $0.55 \mathrm{mmol}, 1.5$ equiv), and radical initiator ( $0.55 \mathrm{mmol}, 1.1$ equiv) in $2.5 \mathrm{~mL}$ solvent under air. [b] Yields and dr were determined on the basis of ${ }^{31} \mathrm{P}$ NMR spectra of crude products. $\mathrm{BEt}_{3}$ (0.1 equiv) was used. [c] The substrate 5 was completely recovered.

The AIBN-mediated reaction [48] did not proceed at room temperature (entry 1). An increase in temperature gave a small amount of the product 7a. Attempts to enhance the yield of $7 \mathbf{a}$ by using a catalytic amount of $\mathrm{BEt}_{3}$ [49] (entry 2) were not successful. As solvents, $\mathrm{CH}_{2} \mathrm{Cl}_{2}$ and THF were not effective (entries 5 and 6). The reaction in $\mathrm{MeOH}$ gave two diastereomers in a ratio of 91:9, and the reaction temperature did not affect this ratio (entries 3 and 4). The molecular structure and absolute configurations at the phosphorus and carbon atoms of the major diastereomer of $7 \mathbf{a}$ were unequivocally determined by $\mathrm{X}$-ray molecular structure analysis [50] (Figure 1). The results showed that the phosphorus and carbon atoms adopted $\mathrm{S}$ configurations.

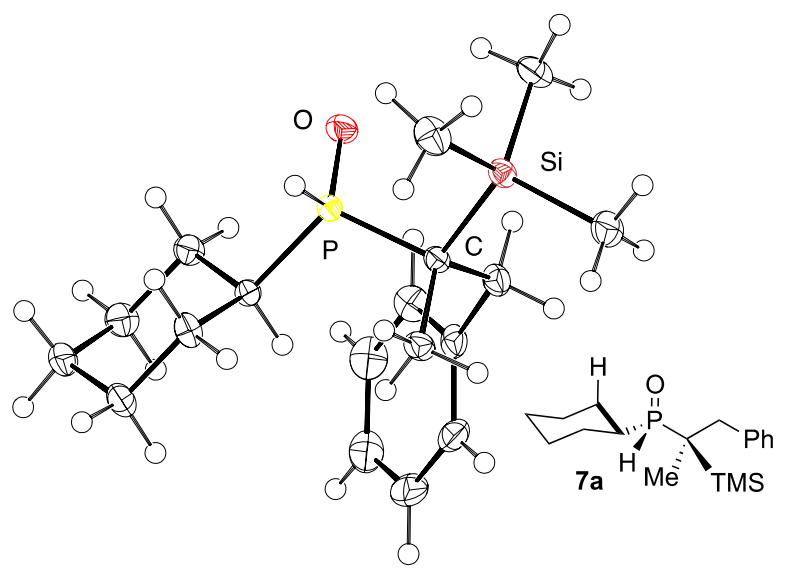

Figure 1. ORTEP drawing of Sp. Sc-7a at the 50\% probability level.

The reaction in Table 1 should begin with the formation of phosphorus-centered radical 8 [51] (Figure 2), which then adds to the alkene 6a. To elucidate the structure of $\mathbf{8}$, molecular orbital calculations at the UHF/6-31G $(\mathrm{d}, \mathrm{p})$ level of theory [52] were carried out. The results showed two stable diastereomers: $\mathbf{8 a}$ and $\mathbf{8 b}$, whereby the radical center at the phosphorus atom was oriented in the same or opposite direction toward the carbon-silicon bond. The diastereomer $\mathbf{8 b}$ was more stable than $8 \mathbf{a}$ by about $0.5 \mathrm{kcal} / \mathrm{mol}$. The relative stability of the major product $7 \mathbf{a}$ and its diastereomer $7 \mathbf{a}^{\prime}$ was also estimated by DFT calculations at the B3LYP/6-31G $(\mathrm{d}, \mathrm{p})$ level of theory. On the basis of these calculations, interconversion of the phosphorus radicals $\mathbf{8 a}$ and $\mathbf{8 b}$ may be possible, but $\mathbf{8 b}$ may mainly attack cyclohexene to form thermodynamically stable diastereomer $\mathbf{7 a}$. 


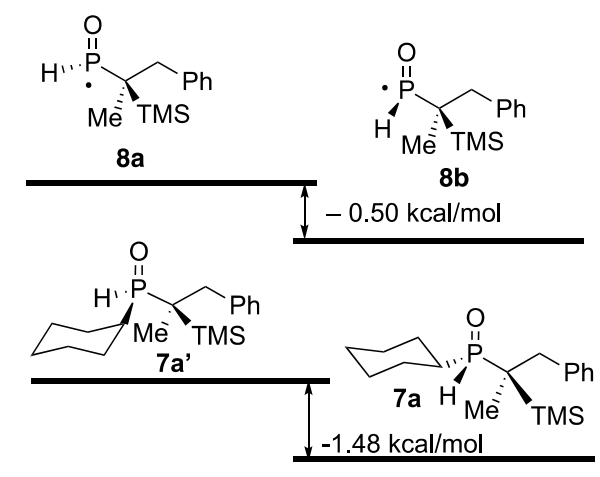

Figure 2. Energy diagram of phosphorus centered radicals $\mathbf{8 a}$ an $\mathbf{8 b}$, and products $7 \mathbf{a}$ and its diastereomer $\mathbf{7} \mathbf{a}^{\prime}$.

We next investigated the scope of alkenes with phosphine oxide 5 under the $\mathrm{BEt}_{3}$ mediated addition reaction conditions (Table 2). Terminal alkenes having hydroxy, trimethylsilyl, acetyl, acetoxy, and acetal groups $6 \mathbf{b}-\mathbf{6 g}$ reacted with the phosphorus-centered radical generated from 5 to give the corresponding products $7 \mathbf{b}-7 \mathbf{f}$ (entries 1-5).

Table 2. Radical addition of 5 to a range of alkenes.

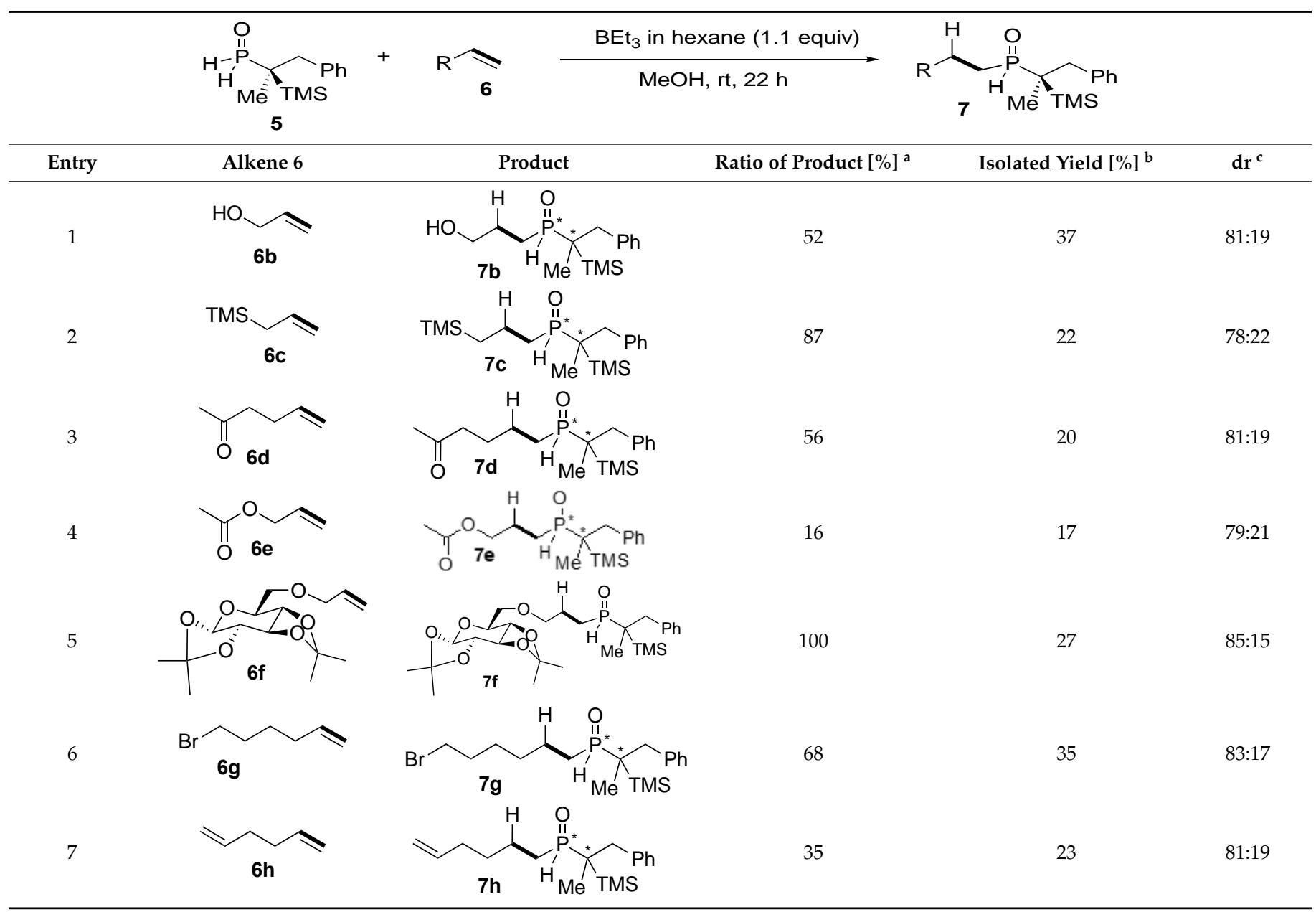

${ }^{a}$ Ratio of product indicates percentage of the integrals of the signals corresponding to the product among all the signals observed in ${ }^{31} \mathrm{P}$ NMR spectra of the crude products. ${ }^{b}$ Yields of isolated products through column chromatography on $\mathrm{Al}_{2} \mathrm{O}_{3}$ and gel permeation chromatography. ${ }^{\mathrm{c}}$ Diastereomric ratio of isolated products determined by ${ }^{31} \mathrm{P}$ NMR spectra. 
In all cases, ${ }^{31} \mathrm{P}$ NMR and ${ }^{1} \mathrm{H}$ NMR spectra showed the formation of anti-Markovnikov adducts (See Supplementary Materials). This regioselectivity is in accordance with the addition reaction of phosphorus-centered radical to terminal alkenes [35]. They were isolated by column chromatography on $\mathrm{Al}_{2} \mathrm{O}_{3}$ and gel permeation chromatography to give the corresponding products with high purity, but in low yields due to their lability during purification. In the isolated product, $7 \mathbf{g}$ from the reaction of 6-bromo-1-hexene $(\mathbf{6 g})$ and a bromine atom remained intact (entry 6). The reaction of 1,5-hexadiene (6h) gave the product $\mathbf{7 h}$, in which only one alkenyl group participated in the reaction (entry 7 ). Products derived from the intramolecular cyclization of a terminal alkene in $7 \mathrm{~h}$ were not observed, which is in a marked contrast to the reported reaction of phosphorus-centered radical to 1,5-hexadiene [35].

Finally, primary phosphines with a terminal alkenyl group were subjected to the radical reaction conditions (Table 3). Reduction in phosphonoselenolate 9a with LAH followed by alkaline aqueous workup generated primary phosphines 11, which were then treated with AIBN in toluene for $2 \mathrm{~h}$. Attempts to purify the crude products failed to give the phosphorus-containing cyclic compounds, probably because of the lability of presumed phospholanes 12, although similar phospholanes were characterized by their NMR spectra [53]. Thus, we treated the reaction mixture containing 12 with a THF solution of $\mathrm{BH}_{3}$ to give boron complexes 13. The use of $9 \mathrm{a}$ and 10a gave boron complexes of phospholanes $13 \mathbf{a}$ and $\mathbf{1 3 b}$, and the reaction of $9 \mathbf{b}$ led to the formation of the boron complex of phosphorinane 13c in high yield with good diastereoselectivities (entries 1-3).

Table 3. Intramolecular cyclization reaction of primary phosphines generated from phosphonoselenoates 9 and phosphonates $\mathbf{1 0 .}$

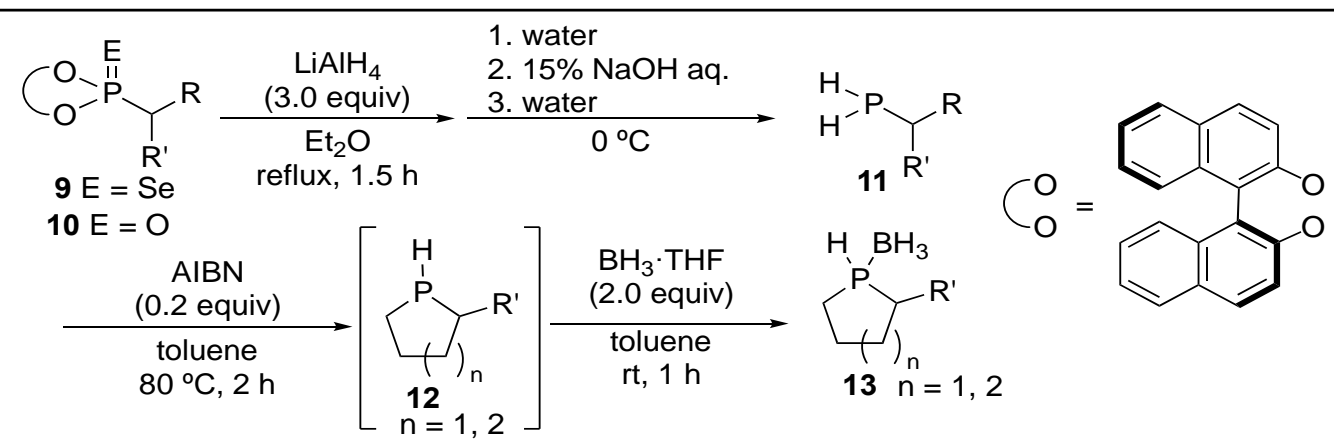

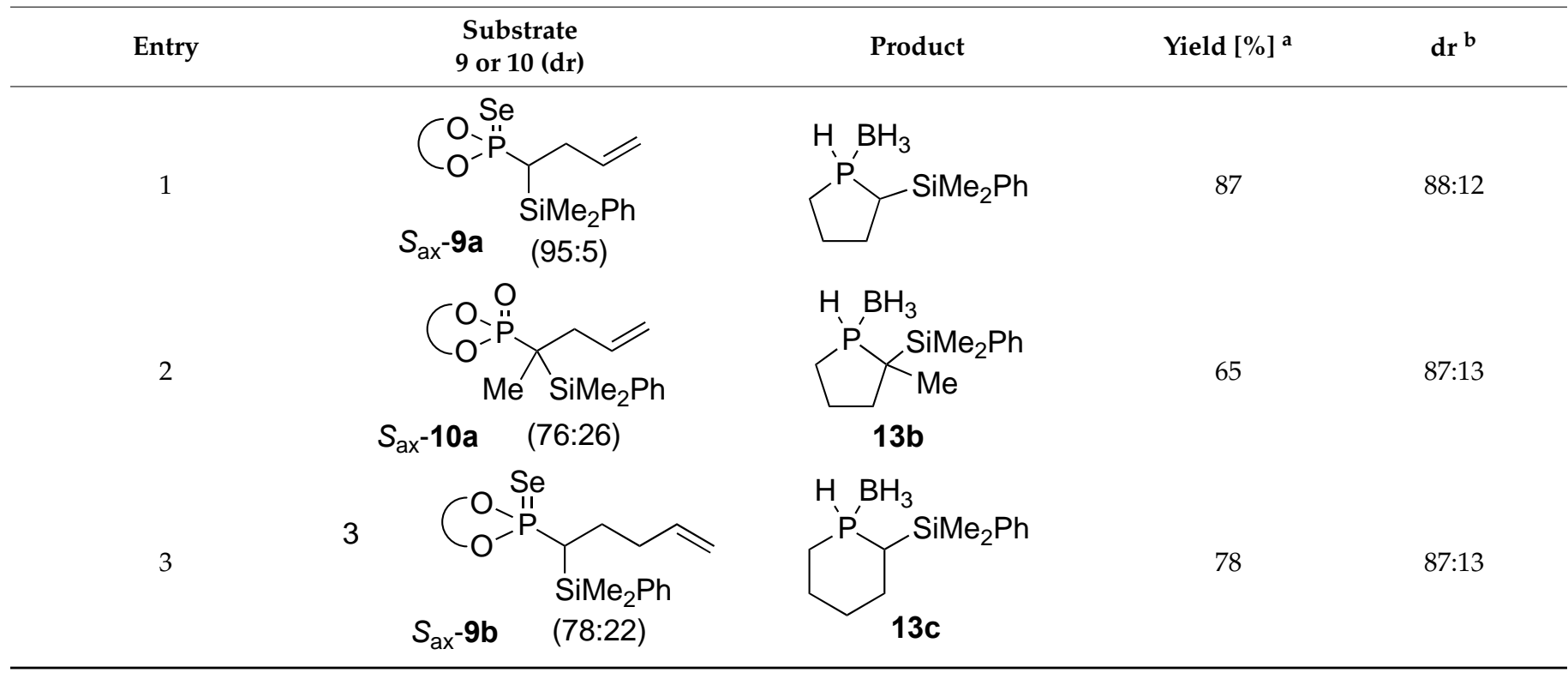

${ }^{a}$ Isolated yields. ${ }^{\mathrm{b}}$ Diastereomric ratio of isolated products determined by ${ }^{31} \mathrm{P}$ NMR spectra. 


\section{Conclusions}

In summary, we have demonstrated the generation of primary phosphines with a stereogenic carbon atom adjacent to the phosphorus atom. The primary phosphine oxide with a tetrasubstituted stereogenic carbon center was subjected to $\mathrm{BEt}_{3}$-mediated radical addition reaction to cyclohexene and terminal alkenes. The reaction gave anti-Markovnikov adducts as major products. Functional groups, such as hydroxy, trimethylsilyl, acetyl, acetoxy, and acetal groups, and bromine atoms remained intact under the reaction conditions. To the best of our knowledge, these products are the first examples of compounds with a successive stereogenic secondary phosphorus atom and tetrasubstituted carbon atom, although organophosphorus compounds with a tetrasubstituted carbon atom next to a phosphorus atom have also been reported to some extent [54-56]. The intramolecular cyclization of in situ-generated primary phosphines with an alkenyl group was achieved to give phospholanes and phosphorinanes, which were isolated as boron complexes. Further studies on organophosphorus compounds with a binaphthyloxy group as key precursors [57] for $P$-stereogenic organophosphorus compounds are in progress.

Supplementary Materials: The following are available online at https://www.mdpi.com/article/ 10.3390/org2040023/s1, Experimental procedure, the detail of X-ray structure analysis, cartesian coordinates of DFT calculation, and ${ }^{1} \mathrm{H}$ and ${ }^{13} \mathrm{NMR}$ spectra of new compounds.

Author Contributions: Conceptualization, T.M.; investigation, R.W., K.I., Y.M., K.K. and M.M.; writing—original draft preparation, T.M.; writing—review and editing, Y.M., K.K. and M.M. All authors have read and agreed to the published version of the manuscript.

Funding: This research received no external funding.

Data Availability Statement: Not applicable.

Acknowledgments: This research was partly supported by a Grant-in-Aid for Scientific Research (B) (19H02712) from MEXT, and JSPS KAKENHI grants 18H04396 (Middle Molecular Strategy). We are also grateful for support from the SPring-8 synchrotron, where synchrotron radiation experiments were performed at the BL02B1 beamline with the approval of the Japan Synchrotron Radiation Research Institute (JASRI) (proposals 2020A0557, 2020A0834, 2020A1056, 2020A1644, 2020A1656, and 2021A1592).

Conflicts of Interest: The authors declare no conflict of interest.

\section{References}

1. Best Synthetic Methods: ORGANOPHOSPHORUS (V) CHEMISTRY; Timperley, C.M., Ed.; Elsevier: London, UK, 2015.

2. Kolodiazhnyi, O.I. Asymmetric Synthesis in Organophosphorus Chemistry; Wiley-VCH: Weinheim, Germany, 2017.

3. Organophosphorus Chemistry; Iaroshenko, V., Ed.; Wiley-VCH: Weinheim, Germany, 2019.

4. Fleming, J.T.; Higham, L.J. Primary phosphine chemistry. Coord. Chem. Rev. 2015, 297, 127-145. [CrossRef]

5. Wang, X.; Xia, C.; Wu, L. Visible-Light-Promoted Photoredox Dehydrogenative Coupling of Phosphines and Thiophenols. Org. Lett. 2020, 22, 7373-7377. [CrossRef]

6. Arockiam, P.B.; Lennert, U.; Graf, C.; Rothfelder, R.; Scott, D.J.; Fischer, T.G.; Zeitler, K.; Wolf, R. Versatile Visible-Light-Driven Synthesis of Asymmetrical Phosphines and Phosphonium Salts. Chem. Eur. J. 2020, 26, 16374-16382. [CrossRef]

7. Bevern, D.; Goerls, H.; Krieck, S.; Westerhausen, M. Synthesis, Structure, and Stability of Lithium Arylphosphanidyldiarylphosphine Oxide. Z. Anorg. Allg. Chem. 2020, 646, 948-958. [CrossRef]

8. Gafurov, Z.N.; Sakhapov, I.F.; Kagilev, A.A.; Kantyukov, A.O.; Khayarov, K.R.; Sinyashin, O.G.; Yakhvarov, D.G. The formation of mesitylphosphine and dimesitylphosphine in the reaction of organonickel s-complex $[\mathrm{NiBr}(\mathrm{Mes})(\mathrm{bpy})](\mathrm{Mes}=2,4,6-$ trimethylphenyl, bpy $=2$, 2'-bipyridine) with phosphine $\mathrm{PH}_{3}$. Phosphorus Sulfur Silicon Relat. Elem. 2020, 195, 726-729. [CrossRef]

9. Oleg, G.; Yakhvarov, D.G.; Wilders, A.M.; Henle, J.; Haibach, M.C.; Swiatowiec, R.; Bien, J.; Henry, R.F.; Asare, S.O.; Wall, A.L.; et al. Pd-Catalyzed Cross-Coupling of Hindered, Electron-Deficient Anilines with Bulky (Hetero)aryl Halides Using Biaryl Phosphorinane Ligands. ACS Catal. 2020, 10, 15008-15018.

10. Navratil, M.; Faria, E.N.; Panahy, G.; Cisarova, I.; Goicoechea, J.M.; Stepnicka, P. Novel ferrocenyl functionalized phosphinecarboxamides: Synthesis, characterization and coordination. Dalton Trans. 2020, 49, 8645-8651. [CrossRef]

11. Han, Z.; Rohner, D.; Samedov, K.; Gates, D.P. Isolable Phosphaalkenes Bearing 2, 4, 6-Trimethoxyphenyl and 2, 6Bis(trifluoromethyl)phenyl as P Substituents. J. Org. Chem. 2020, 85, 14643-14652. [CrossRef]

12. Rafols, L.; Torrente, S.; Aguila, D.; Soto-Cerrato, V.; Perez-Tomas, R.; Gamez, P.; Grabulosa, A. Expanding the Range of Pyrenylphosphines and Their Derived Ru(II)-Arene Complexes. Organometallics 2020, 39, 2959-2971. [CrossRef] 
13. Zimmerman, A.N.; Xu, R.S.; Reynolds, S.C.; Shipp, C.A.; Marshall, D.J.; Wang, G.; Blank, N.F.; Gibbons, S.K.; Hughes, R.P.; Glueck, D.S.; et al. Diastereoselective Synthesis of P-Stereogenic Secondary Phosphine Oxides (SPOs) Bearing a Stereogenic Substituent by Ring Opening of (+)-Limonene Oxide with Primary Phosphido Nucleophiles. J. Org. Chem. 2020, 85, 14516-14526. [CrossRef]

14. Schoemaker, R.; Kossatz, P.; Schwedtmann, K.; Hennersdorf, F.; Weigand, J.J. Coordination Chemistry and Methylation of Mixed-Substituted Tetraphosphetanes (RP-PtBu $)_{2}(\mathrm{R}=\mathrm{Ph}, \mathrm{Py})$. Chem. Eur. J. 2020, 26, 11734-11741. [CrossRef]

15. Itazaki, M.; Matsutani, T.; Nochida, T.; Moriuchi, T.; Nakazawa, H. Convenient synthesis of phosphinecarboxamide and phosphinecarbothioamide by hydrophosphination of isocyanates and isothiocyanates. Chem. Commun. 2020, 56, 443-445. [CrossRef]

16. Del, B.; Janet, E.; Alkorta, I.; Elguero, J. Complexes $\mathrm{H}_{2} \mathrm{CO}: \mathrm{PXH}_{2}$ and $\mathrm{HCO}_{2} \mathrm{H}$ : $\mathrm{PXH}_{2}$ for $\mathrm{X}=\mathrm{NC}, \mathrm{F}, \mathrm{Cl}, \mathrm{CN}, \mathrm{OH}, \mathrm{CCH}, \mathrm{CH} 3$, and H: Pnicogen Bonds and Hydrogen Bonds. ChemPhysChem 2020, 21, 741-748.

17. Scott, D.J.; Cammarata, J.; Schimpf, M.; Wolf, R. Synthesis of monophosphines directly from white phosphorus. Nat. Chem. 2021, 13, 458-464. [CrossRef]

18. Hadlington, T.J.; Kostenko, A.; Driess, M. Synthesis and Coordination Ability of a Donor-Stabilized Bis-Phosphinidene. Chem. Eur. J. 2021, 27, 2476-2482. [CrossRef]

19. Moncea, O.; Poinsot, D.; Fokin, A.A.; Schreiner, P.R.; Hierso, J.-C. Palladium-Catalyzed C2-H Arylation of Unprotected (N-H)Indoles on Water Using Primary Diamantyl Phosphine Oxides as a Class of Primary Phosphine Oxide Ligands. ChemCatChem 2018, 10, 2915-2922. [CrossRef]

20. Horky, F.; Cisarova, I.; Stepnicka, P. Synthesis, Reactivity, and Coordination of Semihomologous dppf Congeners Bearing Primary Phosphine and Primary Phosphine Oxide Groups. Organometallics 2021, 40, 427-441. [CrossRef]

21. Horky, F.; Cisarova, I.; Stepnicka, P. A Stable Primary Phosphane Oxide and Its Heavier Congeners. Chem. Eur. J. 2021, 27, 1282-1285. [CrossRef]

22. Lapshin, I.V.; Cherkasov, A.V.; Asachenko, A.F.; Trifonov, A.A. Ln(II) amido complexes coordinated by ring-expanded Nheterocyclic carbenes-promising catalysts for olefin hydrophosphination. Chem. Commun. 2020, 58, 12913-12916. [CrossRef]

23. Dannenberg, S.G.; Waterman, R. A bench-stable copper photocatalyst for the rapid hydrophosphination of activated and unactivated alkenes. Chem. Commun. 2020, 56, 14219-14222. [CrossRef]

24. Wang, C.; Huang, K.; Ye, J.; Duan, W.-L. Asymmetric Synthesis of P-Stereogenic Secondary Phosphine-Boranes by an Unsymmetric Bisphosphine Pincer-Nickel Complex. J. Am. Chem. Soc. 2021, 143, 5685-5690. [CrossRef]

25. Rauhut, M.M.; Currier, H.A.; Semsel, A.M.; Wystrach, V.P. The free radical addition of phosphines to unsaturated compounds. J. Org. Chem. 1961, 26, 5138-5145. [CrossRef]

26. Alvey, L.J.; Meier, R.; Soos, T.; Bernatis, P.; Gladysz, J.A. Syntheses and carbonyliridium complexes of unsymmetrically substituted fluorous trialkylphosphanes: Precision tuning of electronic properties, including insulation of the perfluoroalkyl groups. Eur. J. Org. Chem. 2000, 1975-1983. [CrossRef]

27. Emnet, C.; Tuba, R.; Gladysz, J.A. Convenient Modular Syntheses of Fluorous Secondary Phosphines and Selected Derivatives. Adv. Synth. Catal. 2005, 347, 1819-1826. [CrossRef]

28. Tuba, R.; Tesevic, V.; Dinh, L.V.; Hampel, F.; Gladysz, J.A. Synthesis, structure, and reactivity of fluorous phosphorus/carbon/phosphorus pincer ligands and metal Complexes. Dalton Trans. 2005, 13, 2275-2283. [CrossRef]

29. Vlad, G.; Richter, F.U.; Horvath, I.T. Synthesis of fluorous trialkyl phosphines with the complete exclusion of $\mathrm{PH}_{3}$. Tetrahedron Lett. 2005, 46, 8605-8608. [CrossRef]

30. Arbuzova, S.N.; Gusarova, N.K.; Trofimov, B.A. Nucleophilic and free-radical additions of phosphines and phosphine chalcogenides to alkenes and alkynes. Arkivoc 2006, V, 12-36. [CrossRef]

31. Coudray, L.; Montchamp, J.-L. Recent Developments in the Addition of Phosphinylidene-Containing Compounds to Unactivated Unsaturated Hydrocarbons: Phosphorus-Carbon Bond Formation by Hydrophosphinylation and Related Processes. Eur. J. Org. Chem. 2008, 2008, 3601-3613. [CrossRef]

32. Parsons, A.F.; Wright, A. Synthesis of Bispyrrolidines by Radical Cyclization of Diallylamines Using phosphorus Hydrides. Synlett 2008, 2008, 2142-2146. [CrossRef]

33. Leca, D.; Fensterbank, L.; Lacote, E.; Malacria, M. Recent advances in the use of phosphorus-centered radicals in organic chemistry. Chem. Soc. Rev. 2005, 34, 858-865. [CrossRef] [PubMed]

34. Sylvain, M.; Paul, T. Reactivity of phosphorus centered radicals. In New Aspects in Phosphorus Chemistry V. Topics in Current Chemistry; Majoral, J.P., Ed.; Springer: Berlin/Heidelberg, Germany, 2005; Volume 250, pp. 43-76.

35. Pan, X.-Q.; Zou, J.-P.; Yi, W.-B.; Zhang, W. Recent advances in sulfur- and phosphorous-centered radical reactions for the formation of S-C and P-C Bonds. Tetrahedron 2015, 71, 7481-7529. [CrossRef]

36. Quint, V.; Noel-Duchesneau, L.; Lagadic, E.; Morlet-Savary, F.; Lalevee, J.; Gaumont, A.-C.; Lakhdar, S. Metal-Free Generation of Phosphorus-Centered Radicals for the Synthesis of Phosphorus-Based Heterocycles. Synthesis 2017, 49, 3444-3452. [CrossRef]

37. Gao, Y.; Tang, G.; Zhao, Y. Recent progress toward organophosphorus compounds based on phosphorus-centered radical difunctionalizations. Phosphorus Sulfur Silicon Relat. Elem. 2017, 192, 589-596. [CrossRef]

38. Ren, W.; Yang, Q.; Yang, S.-D. Applications of transition metal catalyzed P-radical for synthesis of organophosphorus compounds. Pure Appl. Chem. 2019, 91, 87-94. [CrossRef] 
39. Tsuchiya, Y.; Yamaguchi, K.; Miwa, Y.; Kutsumizu, S.; Minoura, M.; Murai, T. N, N-Diarylthiazol-5-amines: Structure-Specific Mechanofluorochromism and White Light Emission in the Solid State. Bull. Chem. Soc. Jpn. 2020, 93, 927-935. [CrossRef]

40. Pamungkas, K.K.P.; Maruyama, T.; Murai, T. Boron complexes of thiazole-bridged 1, 5-bidentate nitrogen ligands: Synthesis and acid-responsive photophysical properties. Org. Biomol. Chem. 2021, 19, 6804-6811. [CrossRef]

41. Maekawa, Y.; Kuwabara, K.; Sugiyama, A.; Iwata, K.; Maruyama, T.; Murai, T. Synthesis of P-Stereogenic Phosphinates via an Axis-to-Center Chirality Transfer by the Reaction of Phosphonates Having a Binaphthyloxy Group with Grignard Reagents. Chem. Lett. 2017, 46, 1068-1071. [CrossRef]

42. Kuwabara, K.; Maekawa, Y.; Minoura, M.; Murai, T. Hydrolysis of Phosphonothioates with a Binaphthyl Group: P-Stereogenic O-Binaphthyl Phosphonothioic Acids and Their Use as Optically Active Ligands and Stereogenic Discriminating Agents. Org. Lett. 2018, 20, 1375-1379. [CrossRef]

43. Kuwabara, K.; Maekawa, Y.; Ebihara, M.; Maruyama, T.; Murai, T. Synthesis of $P$-stereogenic phosphonothioates via alcoholysis of phosphonothioates with a binaphthyl group. Heteroat. Chem. 2018, 29, e21448. [CrossRef]

44. Kuwabara, K.; Maekawa, Y.; Minoura, M.; Maruyama, T.; Murai, T. Chemo- and Stereoselective Alcoholysis of Binaphthyl Phosphonothioates: Straightforward Access to both Stereoisomers of Biologically Relevant P-Stereogenic Phosphonothioates. J. Org. Chem. 2020, 85, 14446-14455. [CrossRef]

45. Hirata, Y.; Kuwabara, K.; Takashima, M.; Murai, T. Hormetic Effects of Binaphthyl Phosphonothioates as Pro-oxidants and Antioxidant. Chem. Res. Toxicol. 2020, 33, 2892-2902. [CrossRef] [PubMed]

46. Maekawa, Y.; Maruyama, T.; Murai, T. Sequential Deprotonation-Alkylation of Binaphthyloxy-Substituted Phosphonochalcogenoates: Stereogenic Tri- and Tetrasubstituted Carbon Centers Adjacent to a Phosphorus Atom. Org. Lett. 2016, 18, 5264-5267. [CrossRef] [PubMed]

47. Bonnaventure, I.; Charette, A.B. Probing the Importance of the Hemistable Site of Bis(phosphine) Monoxide Ligands in the Copper-Catalyzed Addition of Diethylzinc to N-Phosphinoylimines: Discovery of New Effective Stereogenic Ligands. J. Org. Chem. 2008, 73, 6330-6340. [CrossRef] [PubMed]

48. Reznikov, A.N.; Skvortsov, N.K. Synthesis of 5-[3-(diphenylphosphinoyl)propyl]-2-thiobarbituric acid. Russ. J. Gen. Chem. 2008, 78, 320-322. [CrossRef]

49. Jessop, C.M.; Parsons, A.F.; Routledge, A.; Irvine, D.J. Radical addition reactions of phosphorus hydrides: Tuning the reactivity of phosphorus hydrides, the use of microwaves and Horner-Wadsworth-Emmons-type reactions. Eur. J. Org. Chem. 2006, 2006, 1547-1554. [CrossRef]

50. Crystallographic Data for 7a: $\mathrm{C}_{18} \mathrm{H}_{31} \mathrm{OPSi}$, Fw: 322.49, $\mathrm{T}=100 \mathrm{~K}$, orthorhombic, $P 2{ }_{1}{ }_{2}{ }_{1} 21, \mathrm{a}=6.4316(6), \mathrm{b}=13.8703(14), \mathrm{c}=20.916(2)$, $V=1865.9(3), Z=4, D_{\text {calcd }}=1.148 \mathrm{~g} \mathrm{~cm}^{-3}, 4209$ Unique Reflections out of 43417 with $\mathrm{I}>2 \sigma(I)$, Flack $0.05(6), G O F=1.031, R_{1}=$ $00221, w R_{2}($ All Data $)=0.062$. Crystallographic Data Have Been Deposited with the Cambridge Crystallographic Data Centre: Deposition Number CCDC-2101001. Available online: https:/ / www.ccdc.cam.ac.uk/structures/ (accessed on 25 October 2021).

51. Deprele, S.; Montchamp, J.L. Triethylborane-Initiated Room Temperature Radical Addition of Hypophosphites to Olefins: Synthesis of Monosubstituted Phosphinic Acids and Esters. J. Org. Chem. 2001, 66, 6745-6755. [CrossRef]

52. Frisch, M.J.; Trucks, G.W.; Schlegel, H.B.; Scuseria, G.E.; Robb, M.A.; Cheeseman, J.R.; Scalmani, G.; Barone, V.; Petersson, G.A.; Nakatsuji, H.; et al. Gaussian 16, Revision, A.03; Gaussian, Inc.: Wallingford, CT, USA, 2016.

53. Douglass, M.R.; Stern, C.L.; Marks, T.J. Intramolecular Hydrophosphination/Cyclization of Phosphinoalkenes and Phosphinoalkynes Catalyzed by Organolanthanides: Scope, Selectivity, and Mechanism. J. Am. Chem. Soc. 2001, 123, 10221-10238. [CrossRef]

54. Nielsen, M.; Jacobsen, B.C.; Jørgensen, K.A. Asymmetric Organocatalytic Electrophilic Phosphination. Angew. Chem. Int. Ed. 2011, 50, 3211-3214. [CrossRef]

55. Zhao, D.; Mao, L.; Wang, L.; Yang, D.; Wang, R. Catalytic asymmetric construction of tetrasubstituted carbon stereocenters by conjugate addition of dialkyl phosphine oxides to $\beta, \beta$-disubstituted $\alpha, \beta$-unsaturated carbonyl compounds. Chem. Commun. 2012, 48, 889-891. [CrossRef]

56. Liu, S.; Tanabe, Y.; Kuriyama, S.; Sakata, K.; Nishibayashi, Y. Ruthenium-Catalyzed Enantioselective Propargylic Phosphinylation of Propargylic Alcohols with Phosphine Oxides. Angew. Chem. Int. Ed. 2021, 60, 11231-11236. [CrossRef]

57. Gbubele, J.D.; Olszewski, T.K. Asymmetric synthesis of organophosphorus compounds using H-P reagents derived from stereogenic alcohols. Org. Biomol. Chem. 2021, 19, 2823-2846. [CrossRef] [PubMed] 